\title{
MICROCONTROLLER MEASURING CONVERTER OF CAPACITANCE BASED ON TRANSIENTS IN RC CIRCUIT
}

\author{
Aleksandr Vostrukhin ${ }^{1}$, Elena Vakhtina ${ }^{2}$ \\ ${ }^{1}$ Stavropol Technological Institute of Service, Russia; ${ }^{2}$ Stavropol State Agrarian University, Russia \\ avostrukhin@yandex.ru, eavakhtina@yandex.ru
}

\begin{abstract}
The performed work relates to measuring techniques, in particular, to devices for metering physical quantities by capacitive sensors built on microcontroller-based interfacing circuit. One of the major capacitive sensor application areas in agriculture are the technological processes connected to humidity control and management. There is a problem in the need of development software for implementing Arduino-based algorithms that allow the analysis and synthesis of technical solutions for measuring the sensor capacitance using transients in an RC circuit. An algorithm that implements the dependence of the Microcontroller Measuring Converter binary code on the sensor capacity is proposed. An analytical expression that allows calculating the values of quantities necessary for effective interfacing of the capacitive sensor's sensing element with the microcontroller is given. The study results of the Microcontroller Measuring Converter for capacitance varying in the range from 100 to $500 \mathrm{pF}$ are presented. Experimental studies were performed on the basis of Atmel's 8bit ATmega328P microcontroller using the Arduino platform. The results obtained in this work are necessary for designing capacitive intelligent microcontroller-based sensors.
\end{abstract}

Keywords: algorithm, Arduino, binary code, microcontroller, resolution.

\section{Introduction}

The method considered in this paper is widely used for digital measurement techniques of capacitance [1]. The relevance of this method has increased significantly with the advent of microcontrollers [2], giving the possibility of its intellectualization. The Arduino open-source electronics platform has become a recognized tool in the field of embedded control systems among scientists, engineers, teachers and students. The Arduino open-source microcontroller platform has become a recognized tool in the field of embedded control systems among scientists, engineers, teachers and students. Arduino provides opportunities for researching measurement methods and developing new technical solutions based on them, including methods for measuring capacitance.

The problem to be solved is to create Arduino-based tools for the analysis and synthesis of capacitive intelligent sensors using transients in the RC circuit.

The source of information for embedded control systems (ECS) are physical quantity sensors. Currently, 'intelligent' sensors (also called 'smart' sensors) have become widespread [3; 4]. The core of the 'intelligent' sensor (hereinafter simply - sensor) is the microcontroller. In most cases, new sensor functions are implemented by improving the software. The skills to design software for microcontroller-based ECS elements are an urgent task. At the moment, this topic is not fully disclosed [5]. The purpose of this paper is to consider software development issues for implementing the process of converting capacitance into binary code based on classical transients in an RC circuit.

A set of microcontroller with additional external elements, including a sensitive one, is a Microcontroller Measuring Converter (MMC). The main function of MMC is to convert a physical quantity into binary code, which can be transmitted using digital serial interfaces. This article presents studies of MMC for capacitance varying in the range from 100 to $500 \mathrm{pF}$. This is the most common variation range for the humidity sensor capacitance, e.g., HCH-1000 of Honeywell Company [6].

\section{Materials and methods}

Using transients in a RC circuit to convert capacitance and/or resistance into binary code is considered in the scientific sources [7-10]. Using microcontroller-controlled transients in a RC circuit also allows to realize the conversion of an analog signal to a digital one [11].The active introduction of the Arduino hardware/software platform (https://www.arduino.cc/) into the processes of developing intelligent sensors [12-14] and studying microprocessor devices by students at engineering faculties [15-18] have provided a new opportunity to research this method. Arduino is the most affordable budget solution, implemented at the popular family of AVR microcontrollers. While programming Arduino there are used the most actual for information real-time systems languages $\mathrm{C} / \mathrm{C}++$ and Assembler. Arduino contains an extensive assortment of modular hardware and software with an open 
source license, continues to develop and is supported by sufficient amount of literature. Arduino is supported by: the widespread in universities Matlab tool [19]; AVRStudio7 software environment designed for the professional development of software application for 8-bit and 32-bit AVR microcontrollers [20]; the operating system Windows 10 [21].

The experimental MMC of capacitance implemented on the Arduino Uno platform based on the 8-bit ATmega328P microcontroller is shown in Fig. 1.

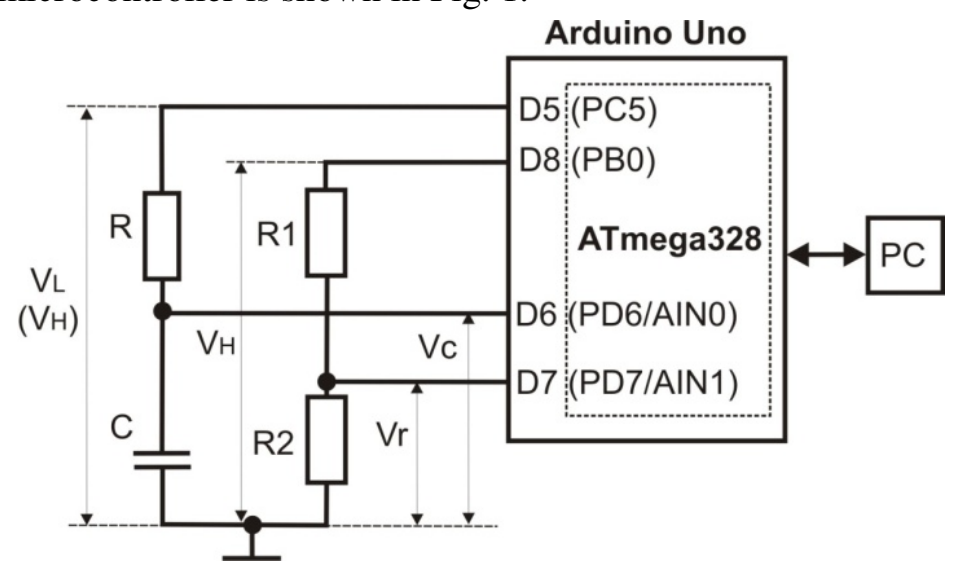

Fig. 1. Scheme of MMC for capacitance

In Fig. 1, the following notation is used: D5, D6, D7, D8 - ArduinoUno device pins; PC5, PD6, PD7, PB0 - ATmega328P microcontroller pins; AIN0 and AIN1 - positive and negative inputs of microcontroller's Analog Comparator; $\mathrm{R}$ - reference resistor which resistance is known; $\mathrm{C}$ - converted (measured) capacitance of the sensor; R1 and R2 - resistive divider.

If the voltage $V c$ at the input AIN0 of the analog comparator exceeds the value of the voltage $V r$, then the logic level at its output will change from ' 0 ' to ' 1 '. When this event occurs, the interrupt system sends a signal to the processor, which proceeds to the subroutine for processing this event. The general algorithm of MMC operation is as follows:

Step 1. The microcontroller outputs a high $V_{H}$ voltage level to the D8(PB0) pin. A reference voltage is formed on the resistor $R_{2}$ and is defined by equation (1):

$$
V_{r}=\frac{V_{H} \cdot R_{2}}{R_{1}+R_{2}},
$$

where $V r-$ reference voltage applied to the analog comparator input AIN1, V.

Step 2. The microcontroller outputs a low voltage level $V_{L}$ to the pin D5(PC5) and maintains this level for some time. The capacitor $C$ is discharged to the voltage $V_{L}$. If a current of $1 \mathrm{~mA}$ flows through the PC5 pin of the microcontroller, then the voltage is $V_{L}<0.05 \mathrm{~V}$ [22]. We admit that $V_{L}=0 \mathrm{~V}$.

Step 3. The microcontroller outputs the voltage $V_{H}$ to the pin D5(PC5) and starts the counter of current time $t$. The voltage $V_{C}$ on the capacitor $C$ begins to increase as shown in Fig. 2.

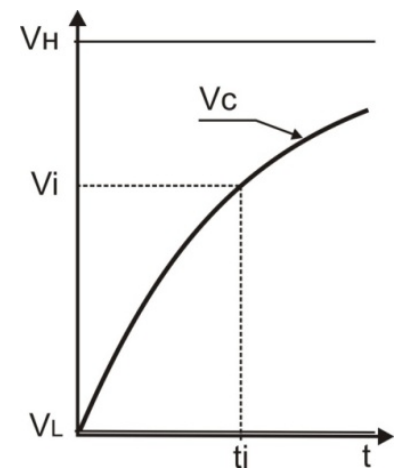

Fig. 2. Changing the voltage $V_{C}$ 
The voltage $V_{C}$ is determined by equation (2):

$$
V_{C}(t)=V_{H} \cdot\left(1-e^{-\frac{t}{R C}}\right),
$$

For any point on the graph $V_{C}(\mathrm{t})$ (Fig. 2), by its coordinates, for example $\left(t_{i}, V_{i}\right)$, it is possible to determine the capacitance $C$ according to equation (3) obtained from (2):

$$
C=\frac{t_{i}}{R \cdot \ln \left(\frac{V_{H}}{V_{H}-V_{i}}\right)} .
$$

A code implementing this algorithm has been developed in the IDE Arduino and registered (https://www1.fips.ru/registers-doc-view/fips_servlet?DB $=$ EVM\&rn $=1860 \& D o c N u m b e r=202061$ 2922\&TypeFile $=$ html).

It should be noted that the MMC in question is universal in relation to RC circuit elements. If in the MMC scheme shown in Fig. $1 C$ - reference capacity which capacitance is known, and $\mathrm{R}-$ converted (measured) resistance of the sensor, then its value can be calculated by a similar equation:

$$
R=\frac{t_{i}}{C \cdot \ln \left(\frac{V_{H}}{V_{H}-V_{i}}\right)} .
$$

$V_{i}$ measurement is performed by comparison with the reference $V_{r}$ by the microcontroller analog comparator. When $V_{C}$ rises above $V_{r}$, then the voltage level will change at the analog comparator output. In this case, we can assume that $V_{C}=V_{r}=V_{i}$. Since $V_{r}$ is known, therefore $V_{i}$ is also known.

The time $t_{i}$ is measured as follows. The microcontroller discharges the capacitor by outputting the $V_{L}$ voltage to the line D5 (PC5). Then it withstands some time, for example,

$$
t_{d}=5 \cdot R \cdot C_{\max },
$$

where $C_{\max }-$ maximum possible sensor capacity, $\mathrm{pF}$.

The microcontroller outputs the $V_{H}$ voltage to the line D5 (PC5) and starts the clock counter. The capacitor $C$ begins to charge. When the $V_{C}=V_{r}$ event occurs, then the binary code $N i$ of the counter will be stored in the Capture Register. The time $t_{i}$ is determined by the equation (4):

$$
t_{i}=N_{i} \cdot T_{c},
$$

where $T_{c}$ - microcontroller clock period (cycle time), s.

$$
T_{C=1} / f_{C},
$$

where $f_{c}$ - microcontroller clock frequency, Hz.

The experimental studies were conducted using a variable capacitor $C$, which appearance is shown in Fig. 3. Arduino Uno power supply, as well as information exchange, including the output of conversion results to a PC monitor, is carried out via a USB port [12-14].

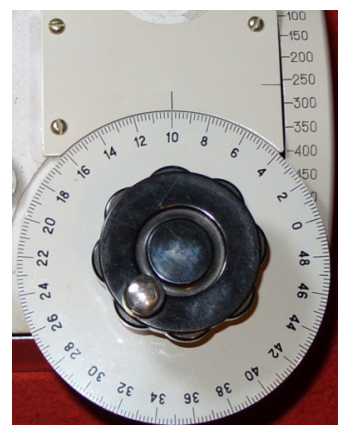

Fig. 3. Variable capacitor with a resolution of $0.2 \mathrm{pF}$ and a capacitance range from 50 to $1150 \mathrm{pF}$ 
The result of converting the capacitance $C$ into a binary code $N$ at $V_{r}=0.632 \cdot V_{H}$ is formed in the microconroller Counter Register (TCNT1) of the timer/counter (TC1) in accordance with the expression (5):

$$
N=R \cdot C / T_{c},
$$

At the microcontroller clock frequency $f_{c}=16 \mathrm{MHz}$, the cycle time $T_{c}=62.5 \mathrm{~ns}$.

For MMC implementation, the variant $V_{r}=0.5 V_{H}$ was used. In this case, $R_{1}=R_{2}$. Then, the capacitance of the sensor $C$ in accordance with (3) is determined by the expression (6):

$$
C=\frac{N_{i} \cdot T_{c}}{\ln \left(\frac{V_{H}}{V_{H}-V_{r}}\right) \cdot R},
$$

Since, in our case, $V_{r}=0.5 V_{H}$, the expression (6) takes the form (7):

$$
C=\frac{N_{i} \cdot T_{c}}{\ln 2 \cdot R}=\frac{N_{i} \cdot T_{c}}{0.693 \cdot R} .
$$

\section{Results}

Let us consider an example of designing the MMC of capacitance for the HCH-1000 air humidity sensor. When the air humidity changes from 0 to $100 \%$, the capacitance of this sensor varies from 280 to $380 \mathrm{pF}$ [6]. It is required to obtain the MMC resolution of $1 \mathrm{pF}$ to measure humidity with a resolution of $1 \%$. In our case, when the sensor capacity changes to $\Delta C=1 \mathrm{pF}$, the transient time should change by one clock period $T_{c}=62.5 \mathrm{~ns}$, and the binary code $\Delta N=1$. The problem solution is reduced to determining the resistance $R$ in the RC circuit (Fig. 1).

In accordance with expression (7) we obtain (8):

$$
\Delta C=\frac{\Delta N \cdot T_{c}}{0.693 \cdot R}, R=\frac{\Delta N \cdot T_{c}}{0.693 \cdot \Delta C}, R=\frac{1 \cdot 62.5}{0.693 \cdot 1}=90.2 \mathrm{k} \Omega .
$$

In the experimental studies the reference resistor $R=100 \mathrm{k} \Omega$ was used. In this case, the MMC capacitance resolution is:

$$
\Delta C=\frac{T_{c}}{R}=\frac{62.5}{100}=0.625 \mathrm{pF} .
$$

Channel $1(\mathrm{CH} 1)$ of the waveform shown in Fig. 4 reflects the voltage $V_{C}$ change on the capacitance $C=205+195=400 \mathrm{pF}$ : where $205 \mathrm{pF}$ - the variable capacitor capacitance; $195 \mathrm{pF}-$ the capacitance of the oscilloscope's connecting probe. The input impedance of the oscilloscope also influences.

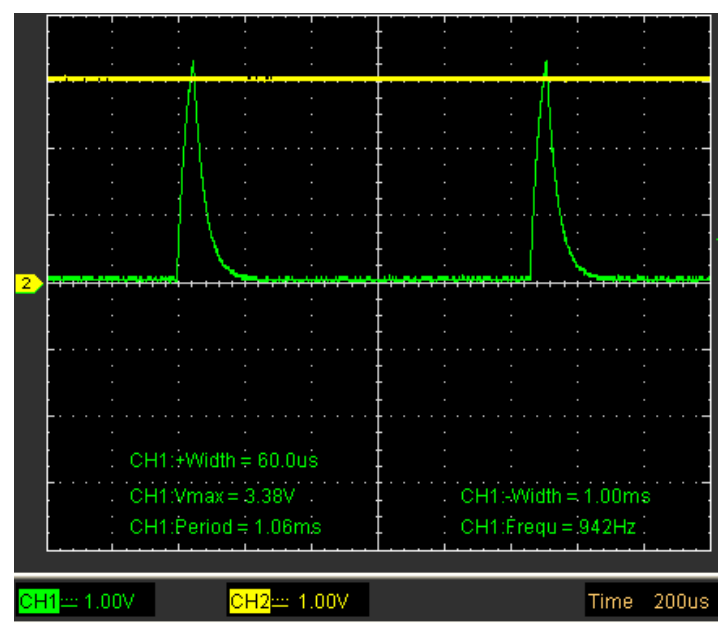

Fig. 4. Oscillogram: channel $1(\mathrm{CH} 1)-$ voltage $V_{C}$ across the capacitance; channel $2(\mathrm{CH} 2)$ - reference voltage $V_{r}$ 
Channel $2(\mathrm{CH} 2)$ reflects the reference voltage $V_{r}=0.632 V_{H}$. The oscillogram shows that the $V_{C}$ voltage continues to increase after crossing the reference voltage $V_{r}$ to the value $V_{\max }=3.38 \mathrm{~V}$. This fact can be explained by the delay of the analog comparator (not more than $0.5 \mu \mathrm{s}$ ) [22] and the execution of several clock cycles of machine instructions by the microcontroller. The waveform also shows other parameters of the channel 1 signal, for example: period $=1.06 \mathrm{~ms}$; frequency of conversion cycles Frequ $=942 \mathrm{~Hz}$, etc.

Experimental dependences of the MMC binary code $N$ on the capacitance $C$ are shown in Fig. 5.

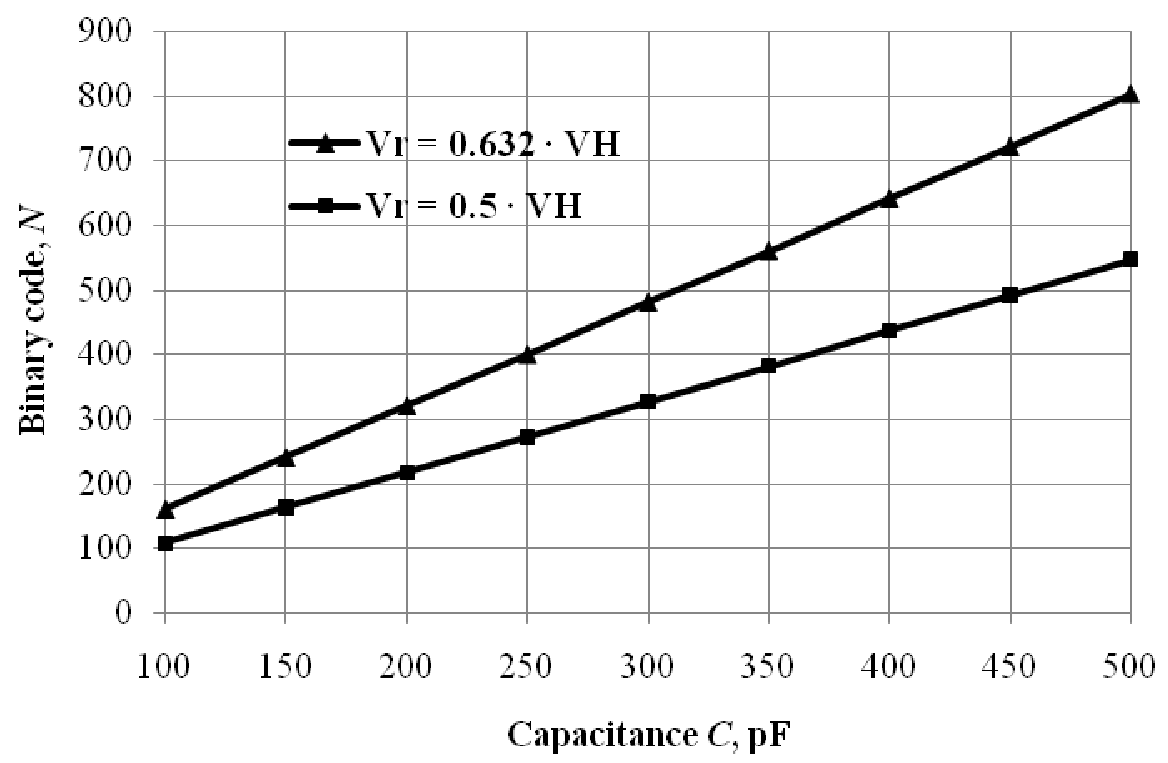

Fig. 5. Dependencies of binary code $N$ of MMC on capacitance $C$ at $R=100 \mathrm{k} \Omega$

The experiment was performed for two cases: $V_{r}=0.632 \cdot V_{H} \approx 3.06 \mathrm{~V}$ and $V_{r}=0.5 \cdot V_{H} \approx 2.42 \mathrm{~V}$ (when the MMC was powered from USB $V_{H} \approx 4.84 \mathrm{~V}$ and from an external source $V_{H} \approx 4.98 \mathrm{~V}$ ). The power supply voltage of the microcontroller changed by about $3 \%$ and the result of converting the capacitance to binary code was not affected.

\section{Conclusions}

1. The analytical expressions presented in this paper allow calculating the main MMC parameters depending on the microcontroller clock frequency and the capacitive sensor resolution.

2. The MMC conversion characteristic is linear and its slope does not depend on fluctuations in the supply voltage in the range of 3-4\%.

3. The study results can be used to design MMC based on microcontrollers of other manufacturers.

4. The MMC algorithm and code can be used to study microprocessor measuring devices in engineering education.

\section{References}

[1] Rathore T.S. Digital Measurement Techniques, 2nd ed., Alpha Science International Ltd., Pangbourne, England, 2003. 309 p.

[2] Schönfelder G, Schneider C. Messtechnik mit dem Atmega (Deutsch), Franzis-Verlag, 2010. $284 \mathrm{p}$.

[3] Huddleston C. Intelligent sensor design using the microchip dsPIC. Burlington, USA: Elsevier, 2007. $303 \mathrm{p}$.

[4] Galar D., Kumar U. eMaintenance: Essential Electronic Tools for Efficiency. Academic Press, 2017. $552 \mathrm{p}$.

[5] Платунов А. Встраиваемые системы управления (Embedded control systems). Control Engineering Россия. 2013, No1 (43), pp. 16-24. (In Russian).

[6] HCH-1000 Series Capacitive Humidity Sensors Datasheet. [online] [12.03.2020]. Available at https://www.alldatasheet.com/datasheet-pdf/pdf/230829/HONEYWELL/HCH-1000.html 
[7] Лаптев B. Цифровой измеритель температуры на базе AVR-микроконтроллера и RCцепочки (A digital temperature meter based on an AVR microcontroller and an RC chain). Electronic components: Электронные компоненты, 2003, No. 2, pp. 46 - 49. (In Russian).

[8] Вострухин А.В., Вахтина Е.А. Пат. 2392629 РФ на изобретение. Устройство микроконтроллерное для измерения емкости и сопротивления. (Pat. 2392629. Microcontroller device for capacity and resistance measurement). Stavropol State Agrarian University, Stavropol, Russia, 2010, bulletin No 17. (In Russian). [online] [23.03.2020]. Available at: http://www.freepatent.ru/images/patents/70/2392629/patent-2392629.pdf

[9] Вострухин А.В., Вахтина Е.А., Болдырев И.А. Пат. № 2697715 РФ на изобретение. Микроконтроллерное измерительное устройство емкости для встраиваемых вычислительных систем. (Pat. 2697715. Microcontroller capacitance measuring device for embedded computing systems) Stavropol State Agrarian University, Stavropol, Russia, 2019, bulletin No 23. (In Russian). [online] [30.04.2020]. Available at: https://patents.s3.yandex.net/RU2697715C1_20190819.pdf

[10] Вострухин А.В., Вахтина Е.А., Болдырев И.А. Пат. № 2698492 РФ на изобретение. Микроконтроллерное измерительное устройство емкости для встраиваемых вычислительных систем контроля и управления. (Pat. 2698492. Microcontroller capacitance measuring device for embedded computing systems of control and management) Stavropol State Agrarian University, Stavropol, Russia, 2019, bulletin No 25. (In Russian). [online] [30.04.2020]. Available at: https://patents.s3.yandex.net/RU2698492C1_20190828.pdf

[11] Vostrukhin A., Vakhtina E. Analog-to-digital Converter based on the transient process in RC circuit. Proceedings of the 14th International Scientific Conference "Engineering for Rural Development", May 20-22, 2015, Latvia University of Agriculture, vol. 14, pp. 452-457. [online][25.12.2019]. Available at: http://www.tf.llu.lv/conference/proceedings2015/Papers/074_ Vostrukhin.pdf.

[12] Igoe T. Making Things Talk: Using Sensors, Networks, and Arduino to see, hear, and feel your world. O'Reilly Media, 2011. 496 p.

[13]Петин В.А. Проекты с использованием контроллера Arduino (Projects using Arduino controller). 2nd ed. SPb.: BHV-Petersburg, 2015. 446 p. (In Russian).

[14] Blum J. Exploring Arduino: Tools and Techniques for Engineering Wizardry. Wiley, 2013. 384 p.

[15] Yoder R. B. An Arduino-Based Alternative to the Traditional Electronics Laboratory. 2015 BFY Proceedings. July 22-24, 2015, Published by the American Association of Physics Teachers, pp. 107-110. [online][24.22.2020]. Available at: https://advlabs.aapt.org/items/detail.cfm?ID = 13820 .

[16] Vostrukhin A., Vakhtina E. 2016. Studying Digital Signal Processing on Arduino Based platform. Proceedings of the 15th International Scientific Conference "Engineering for Rural Development", May 25-27, 2016, Latvia University of Agriculture, vol. 15, pp. 236-241. [online] [30.01.2020]. Available at: http://www.tf.llu.lv/conference/proceedings2016/Papers /N043.pdf.

[17]Zachariadou K., Yiasemides K., Trougkakos N. A Low-Cost Computer-Controlled ArduinoBased Educational Laboratory System for Teaching the Fundamentals of Photovoltaic Cells. European Journal of Physics, vol. 33(6), 2012, pp. 1599-1610.

[18] Arduino as a programmable logic controller (PLC) [online] [20.03.2020]. Available at: https://www.open-electronics.org/arduino-as-a-programmable-logic-controller-plc/.

[19] Arduino Support from MATLAB. [online] [15.01.2020]. Available at: http://uk.mathworks.com/hardware-support/arduino-matlab.html.

[20] Arduino programming with Atmel Studio. [online] [18.02.2020]. Available at: http://www.visualmicro.com/page/Arduino-for-Atmel-Studio.aspx

[21] Microsoft brings Windows 10 to Makers. Arduino Partnership. [online] [25.01.2020]. Available at: https://blogs.windows.com/buildingapps/2015/04/29/microsoft-brings-windows-10-to-makers

[22] ATmega328/P. Datasheet complete. [online] [04.03.2020]. Available at http://mkprog.ru/wpcontent/uploads/2017/09/ATmega328-328P_Datasheet.pdf. 